\title{
Phylogenetic Analysis of Torque Teno Virus in Thalassemic Children in Egypt
}

\author{
Noha A. Hassuna ${ }^{a}$ Eman Naguib $^{b}$ Medhat Abdel-Fatah $^{b}$ \\ Suzan M. Omar Mousac \\ aDepartment of Medical Microbiology and Immunology, Faculty of Medicine, Minia University, Minia, \\ ${ }^{b}$ Department of Botany and Microbiology, Faculty of Science, Beni Suef University, Beni Suef, and 'Department of \\ Pediatrics, Faculty of Medicine, Minia University, Minia, Egypt
}

\section{Keywords}

Torque teno virus · Thalassemia · Phylogenetic analysis

\begin{abstract}
Objective: Torque teno virus (TTV) is a ubiquitous virus that is commonly associated with blood transfusion. The main aims of this study were to evaluate the incidence of TTV in polytransfused children with thalassemia and to determine for the first time the prevalent TTV genotypes in Egypt. Methods: TTV was detected in 2 groups by nested PCR: the first group comprised 200 children with thalassemia, and the second included age- and sex-matched healthy children with no history of blood transfusion. Results: TTV was detected in 60 and 57\%, respectively, of the children with thalassemia and the healthy children. Among the TTV-positive children with thalassemia, $71.6 \%$ were HCV positive. No hepatitis $B$ surface antigen was detected in the thalassemic children. Significant elevations of alanine transaminase and aspartate transaminase were found in TTV-positive patients with thalassemia compared to TTV-negative patients. Phylogenetic analysis of sequenced TTV isolates showed close relationships to genotypes 1 and 2. Conclusion: TTV is highly prevalent among children with thalassemia in Egypt, with a relatively high infection rate also detected among healthy children.

(c) 2017 S. Karger AG, Basel
\end{abstract}

(C) 2017 S. Karger AG, Basel

\section{KARGER}

E-Mail karger@karger.com

www.karger.com/int

\section{Introduction}

Torque teno virus (TTV) is a single-stranded circular DNA virus, which was isolated for the first time from a Japanese patient in 1997 [1]. The virus belongs to the Anelloviridae family [2]. According to phylogenetic studies, there are 7 main genetic groups of this virus (i.e., 1-7), with each including several genotypes $[3,4]$. The virus genome consists of an untranslated region that is conserved and a coding region including at least 2-3 open reading frames (ORF) [5]. The main method for TTV diagnosis is nested PCR using primers directed against the N22 region in ORF1, which mainly detects the first 6 TTV genotypes, or against the untranslated region $[6,7]$.

TTV is a common worldwide virus, but it has a characteristic geographical distribution with a marked genomic diversity $[5,8]$. In spite of its high prevalence, very little is known about the role of TTV and its correlation with various diseases [9]. An association between TTV and hepatitis $\mathrm{C}$ virus (HCV) has been reported; TTV has even been used as a prognostic marker for HCV infection outcomes [10-13]. Moreover, the virus has been associated with various tumors and it is now considered a carcinogen [14]. Owing to their dependency on blood transfusions, $\beta$-thalassemia major patients are highly vulnerable to transfusion-transmitted infections, particularly

Noha A. Hassuna

Department of Medical Microbiology and Immunology Faculty of Medicine, Minia University

Minia 61111 (Egypt)

E-Mail nohaanwar@mu.edu.eg 
hepatitis viruses, although the incidence of the latter has been reduced by proper screening. Nevertheless, liver enzymes have been found to be elevated in several thalassemia patients even in the absence of hepatitis virus infection [15]. The presence of TTV has been demonstrated in a considerable proportion of hemophiliac patients suffering from fulminant hepatitis of unknown origin in addition to healthy blood donors in the UK and Japan [16]. Moreover, a high prevalence of TTV (reaching up to $100 \%)$ has been observed in a wide range of thalassemia patients in various studies [17].

The aims of the present study were to determine the incidence of TTV infection among children with $\beta$ thalassemia in Egypt, to evaluate coinfection with $\mathrm{HCV}$, and to phylogenetically analyze TTV isolates to determine the prevalent genotypes.

\section{Materials and Methods}

This study included 200 children (patient group) with thalassemia who received at least 3 blood transfusions per month. A control group of 200 age- and sex-matched healthy children (normal serum transaminase levels with no clinical evidence of liver diseases, negative for hepatitis $\mathrm{B}$ surface antigen [HBsAg] and anti-HCV, and with no history of blood transfusion) was also included. This study was carried out according to the principles of the Declaration of Helsinki and it was approved by the Ethics Committee of the Science Faculty. Informed consent was obtained from the parents of all of the children.

\section{Patient Information and Investigation}

History Taking. The medical records of the patients and healthy children were reviewed to obtain demographic data such as age, sex, underlying diseases, surgical procedures, and transfusion history including numbers of both blood transfusions and units transfused to each patient.

Laboratory Investigation. A 5-mL blood sample was collected from patients at the time of transfusion. Serum was collected from $2 \mathrm{~mL}$ of blood and stored at $-80^{\circ} \mathrm{C}$ until virological and biochemical laboratory tests. The remaining $3 \mathrm{~mL}$ of whole blood were used for detection of TTV.

Virological and Biochemical Laboratory Tests

Alanine amino transferase (ALT) and aspartate transferase [18] levels were measured on a Diatron apparatus (Pictus B+) using a kit according to the manufacturer's instructions (BioSystems S.A., Spain). Values $\geq 41 \mathrm{IU} / \mathrm{L}$ for ALT and $\geq 40 \mathrm{IU} / \mathrm{L}$ for AST were considered abnormal. $\mathrm{HCV}$ antibodies (HCV-Ab) and HBsAg were determined using a mini-VIDAS apparatus (bioMérieux, France) and cut-off values were calculated according to manufacturer's instructions.

Isolation and Detection of TTV DNA by Nested PCR

DNA Extraction. DNA was extracted from whole blood using a High Pure Viral Nucleic Acid Kit (Promega, USA) in accordance with the manufacturer's instructions. DNA was stored at $-20^{\circ} \mathrm{C}$.

TTV Phylogenetic Analysis in

Thalassemic Children
Nested PCR. Nested PCR protocols were employed simultaneously for each sample to detect TTV ORF1 (N22 region). The region of ORF1 spanning nucleotides 915-2,185 of TTV was amplified. For the first PCR, the forward primer was A5430 (5' ${ }^{\prime}$-CAGACAGAGGAGAAGGCAACATG- $3^{\prime}$ ) and the reverse primer was A5432 (5'-CTACCTCCTGGCATTTTACCA-3') [19]. PCR were performed in $50 \mu \mathrm{L}$ containing $25 \mu \mathrm{L}$ of Master Mix (DreamTaq Green Master Mix; Thermo Scientific, USA), $1 \mu \mathrm{L}$ of each primer, $5 \mu \mathrm{L}$ of template DNA, and $18 \mu \mathrm{L}$ of sterile, nuclease-free water. The PCR included 35 cycles: $30 \mathrm{~s}$ of denaturation at $94^{\circ} \mathrm{C}, 30 \mathrm{~s}$ of annealing at $58^{\circ} \mathrm{C}$, and $45 \mathrm{~s}$ of elongation at $72^{\circ} \mathrm{C}$. The final cycle was followed by a 7 -min incubation at $72^{\circ} \mathrm{C}$. For the second round of PCR, the forward primer was A7861 (5'-GGMAAYATGYTRTGGATAGACTGG-3') and the reverse primer was NG063 $\left(5^{\prime}\right.$-CTGGCATTTTACCATTTCCAAAGTT- $\left.{ }^{\prime}\right)$ [19]. The PCR was carried out using the same mixture as above except for the primers. The cycling conditions were similar to those of the firstround PCR, except that the number of cycles was 25. The PCR products were separated on $2 \%$ agarose gels and visualized under ultraviolet light.

DNA Sequencing and Phylogenetic Analysis

The amplicons of the inner round of the nested PCR were purified and sequenced in both directions using an ABI 3500 Genetic Analyzer and a BigDye ${ }^{\circledR}$ Terminator V 3.1 Cycle Sequencing Kit (Applied Biosystems, Foster City, CA, USA). Raw DNA sequence reads were edited and assembled into contigs using Vector NTI Express ${ }^{\circledR}$ 1.2.0 (Thermo-Fisher Scientific). To confirm that the obtained sequences were from TTV, they were compared to sequences in the GenBank library using the Basic Local Alignment Search Tool (BLAST; NCBI). Multiple sequence alignment and phylogenetic analysis of the selected obtained sequences and reference sequences of the main genogroups obtained from the database were performed using Molecular Evolutionary Genetics Analysis (MEGA) software version 7.0 [20]. The evolutionary history was measured via the neighbor-joining method [21]. A bootstrap consensus tree based on 500 replicates was obtained to represent the evolutionary history of the analyzed taxa [22]. The percentage of replicate trees in which the associated taxa clustered together in the bootstrap test (500 replicates) is shown next to the branches. The maximum composite likelihood method was used to compute evolutionary distances in units of the number of base substitutions per site [23].

\section{Statistical Analysis}

Statistical analysis was performed using Prism 5 and SPSS 16.0 for Windows. Data are shown as means \pm SD for quantitative variables and percentages for categorical variables. Comparisons between groups were performed using Student's $t$ test to compare two independent means for continuous variables and the $\chi^{2}$ test (or Fisher's exact test if required) for categorical variables.

\section{Results}

Two hundred children with thalassemia with a mean age of $7.5 \pm 3.3$ years and 200 healthy children with a mean age of $7.6 \pm 2.8$ years were evaluated. Of the children with thalassemia, 126 were males with mean age of

Intervirology 2017;60:102-108 
Table 1. Levels of liver enzymes in the thalassemic group and the control group

\begin{tabular}{|c|c|c|c|c|c|c|c|c|c|}
\hline & \multicolumn{4}{|c|}{ Thalassemic children } & \multicolumn{4}{|l|}{ Controls } & \multirow{2}{*}{$\begin{array}{l}p \\
\text { value }\end{array}$} \\
\hline & $\begin{array}{l}\text { TTV-positive } \\
(n=120)\end{array}$ & $\begin{array}{l}\text { TTV-negative } \\
(n=80)\end{array}$ & $\begin{array}{l}p \\
\text { value }\end{array}$ & $\begin{array}{l}\text { total } \\
(n=200)\end{array}$ & $\begin{array}{l}\text { TTV-positive } \\
(n=114)\end{array}$ & $\begin{array}{l}\text { TTV-negative } \\
(n=86)\end{array}$ & $\begin{array}{l}p \\
\text { value }\end{array}$ & $\begin{array}{l}\text { total } \\
(n=200)\end{array}$ & \\
\hline ALT & $51.5 \pm 20.4$ & $31.9 \pm 26.3$ & $<0.0001$ & $43.7 \pm 27.7$ & $21.05 \pm 3.13$ & $20.65 \pm 2.7$ & $<0.5$ & $20.9 \pm 2.9$ & $<0.0001$ \\
\hline AST & $54.1 \pm 21.5$ & $34.3 \pm 27.5$ & $<0.0001$ & $46.2 \pm 25.9$ & $20.0 \pm 2.83$ & $19.6 \pm 2.67$ & $<0.51$ & $19.8 \pm 2.75$ & $<0.0001$ \\
\hline
\end{tabular}

Values are presented as means \pm SD. ALT, alanine aminotransferase; AST, aspartate transferase; TTV, torque teno virus. $p<0.05$ is considered statistically significant.

Table 2. Demographic and clinical data for the TTV-positive and TTV-negative thalassemia patients

\begin{tabular}{|c|c|c|c|c|c|c|c|c|c|}
\hline \multirow[t]{2}{*}{ Variable } & \multicolumn{4}{|c|}{ TTV-positive } & \multicolumn{4}{|c|}{ TTV-negative } & \multirow{2}{*}{$\begin{array}{l}p \\
\text { value }\end{array}$} \\
\hline & $\begin{array}{l}\text { boys } \\
(n=64)\end{array}$ & $\begin{array}{l}\text { girls } \\
(n=56)\end{array}$ & $\begin{array}{l}p \\
\text { value }\end{array}$ & $\begin{array}{l}\text { total } \\
(n=120)\end{array}$ & $\begin{array}{l}\text { boys } \\
(n=62)\end{array}$ & $\begin{array}{l}\text { girls } \\
(n=18)\end{array}$ & $\begin{array}{l}p \\
\text { value }\end{array}$ & $\begin{array}{l}\text { total } \\
(n=80)\end{array}$ & \\
\hline Age, years & $7.3 \pm 2.9$ & $6.6 \pm 2.7$ & 0.3 & $7.00 \pm 2.8$ & $8.5 \pm 4.1$ & $7.1 \pm 1.7$ & 0.3 & $8.2 \pm 3.7$ & 0.06 \\
\hline $\begin{array}{l}\text { Transfusion duration, } \\
\text { months }\end{array}$ & $66 \pm 34.7$ & $58.7 \pm 31.04$ & 0.3 & $26.6 \pm 33$ & $79 \pm 42.2$ & $64 \pm 24.7$ & 0.32 & $75.6 \pm 39.2$ & 0.08 \\
\hline ALT, IU/L & $55.7 \pm 22$ & $46.7 \pm 17.5$ & 0.09 & $51.5 \pm 20.4$ & $32.3 \pm 27.6$ & $30.9 \pm 22.5$ & 0.9 & $31.9 \pm 26.3$ & 0.0001 \\
\hline AST, IU/L & $58.3 \pm 23.9$ & $49.3 \pm 17.7$ & 0.1 & $54.1 \pm 21.5$ & $34.3 \pm 28.9$ & $34.2 \pm 23.1$ & 0.1 & $34.3 \pm 27.5$ & 0.0001 \\
\hline $\mathrm{HCV}+, n(\%)$ & $48(75)$ & $38(68)$ & 0.5 & $86(71.6)$ & $20(32)$ & $6(33)$ & 0.9 & $26(32.5)$ & $<0.05$ \\
\hline
\end{tabular}

Values are presented as means \pm SD or numbers (\%). ALT, alanine aminotransferase; AST, aspartate transferase; TTV, torque teno virus; $\mathrm{HCV}$, hepatitis $\mathrm{C}$ virus.

$7.9 \pm 3.6$, and 74 were females with mean age $6.7 \pm 2.5$ $(p=0.78)$. In the control group, 120 were male with a mean age of $7.5 \pm 2.6$ and 80 were female with mean age of $7.5 \pm 3.2(p=0.98)$.

Among the children with thalassemia, $60 \%$ had TTV, while $57 \%$ of the controls were TTV positive $(p=0.17$ ). HCV IgG was detected in 112 thalassemia patients (68 boys and 44 girls), while HBsAg was not detected in the patient group.

Significant increases in ALT and AST levels were observed among the thalassemia patients $(43.7 \pm 27.7$ and $46.2 \pm 25.9 \mathrm{IU} / \mathrm{L}$, respectively) compared to the control group $(20.9 \pm 2.9$ and $19.8 \pm 2.75 \mathrm{IU} / \mathrm{L}$, respectively; $p<$ $0.05)$. In the children with thalassemia, there was a significant difference in ALT and AST levels between TTVpositive patients and TTV-negative patients $(p=0.05)$, while there was no significant difference in the levels of either enzyme among the healthy individuals $(p=0.5$; Table 1).

Regarding HCV seropositivity, $71.6 \%$ (86/120) of the TTV-positive children with thalassemia were HCV sero- positive, whereas $32.5 \%(26 / 80)$ of the TTV-negative patients were positive $(p<0.05)$ (Table 2$)$. Among the TTVpositive patients with thalassemia, there were no significant differences in mean age, transfusion duration, ALT and AST levels, or anti-HCV Ab status between males and females. Similarly, among the TTV-negative patients with thalassemia, mean age, transfusion duration, and anti-HCV Ab status did not differ significantly between boys and girls.

Patients were further subdivided into 4 subgroups based on their positivity for HCV and TTV (i.e., TTVnegative/HCV-negative, TTV-negative/HCV-positive, TTV-positive/HCV-negative, and TTV-positive/HCVpositive). The mean plasma levels of ALT and AST in these groups were compared. There was a significant difference in liver enzymes in the following groups: TTV-negative/HCV-negative compared to TTV-positive/HCV-positive, TTV-negative/HCV-negative compared to TTV-negative/HCV-positive, TTV-positive/ HCV-negative compared to TTV-positive/HCV-positive, and TTV-positive/HCV-negative compared to TTV- 
Table 3. Comparison of mean plasma levels of ALT and AST in TTV-negative/HCV-negative, TTV-negative/HCV-positive, TTV-positive/HCV-negative, and TTV-positive/HCV-positive patients

\begin{tabular}{llll}
\hline & TTV-negative/HCV-negative $(n=52)$ & TTV-positive/HCV-negative $(n=34)$ & $p$ value \\
\hline ALT & $17.7 \pm 9.98$ & $25.7 \pm 5.8$ & 0.005 \\
AST & $19.5 \pm 9.9$ & $28.7 \pm 9.1$ & 0.004 \\
\hline & TTV-positive /HCV-negative $(n=34)$ & TTV-positive/HCV-positive $(n=86)$ & $p$ value \\
\hline ALT & $25.7 \pm 5.8$ & $61.7 \pm 13.9$ & $<0.0001$ \\
AST & $28.7 \pm 9.1$ & $64.2 \pm 15.98$ & $<0.0001$ \\
\hline & TTV-negative/HCV-positive $(n=26)$ & TTV-positive/HCV-positive $(n=86)$ & $p$ value \\
\hline ALT & $61.8 \pm 24.7$ & $61.7 \pm 13.9$ & 0.99 \\
AST & $65.1 \pm 27.01$ & $64.2 \pm 15.98$ & 0.88 \\
\hline
\end{tabular}

Values are presented as means \pm SD (in IU/L). ALT, alanine aminotransferase; AST, aspartate transferase; TTV, torque teno virus; $\mathrm{HCV}$, hepatitis $\mathrm{C}$ virus. Tukey's multiple comparisons test.

negative/HCV-positive (Table 3). There was no significant difference in ALT or AST levels in the following groups: TTV-positive/HCV-positive vs. TTV-negative/ $\mathrm{HCV}$-positive and TTV-negative/HCV-negative vs. TTV-positive/HCV-negative.

Five TTV isolates were randomly selected for DNA sequencing, i.e., 3 from TTV-positive/HCV-positive patients and 2 from TTV-positive/HCV-negative patients. The sequences obtained were submitted to GenBank (accession No. KY509541 to KY509545). Multiple sequence alignment was performed on the amplicons (after exclusion of the sequencing primers) and the TTV reference sequences obtained from GenBank, using MEGA 7 software. The isolated TTV from patients with thalassemia showed sequence identities ranging between 74.76 and $100 \%$. Eleven of the TTV isolates were closely related to genotype 1 ( 7 from HCV-positive and 4 from HCVnegative patients), 3 were related to genotype 2 (all were from $\mathrm{HCV}$-negative patients) and only 1 was related to genotype 6 (Fig. 1).

\section{Discussion}

TTV infection is one of the most ubiquitous viruses in humans and this infection has been suggested to be related to various diseases, although there is no direct proof of such association [9]. HCV infection is one of the commonest infections encountered with TTV, with several studies reporting such association. However, very little is

TTV Phylogenetic Analysis in Thalassemic Children known about the prevalence of TTV in Egypt, and there is no available data on the commonest genotypes in that country.

Out of 200 children with thalassemia, $60 \%$ were TTV positive and $57 \%$ of the controls were TTV positive. The prevalence of TTV varies worldwide depending on the primers used and the study group selected; thus, it is difficult to compare studies. One study carried out in the Emirates showed a high prevalence of TTV among nonEmirati nationals (89\%) compared to nationals (34.9\%), but the study involved a mixed population of healthy and $\mathrm{HCV}$ and HBV patients and used the more conserved untranslated region of the virus DNA [24]. Another study in Qatar showed a similarly high prevalence, between 81 and $90 \%$, but again it was carried out in healthy as well as $\mathrm{HCV}$-infected patients and it included people of different nationalities [13].

In the present work, among the 120 TTV-positive thalassemia patients, 86 (71.6\%) were HCV seropositive, while only 26 of $80 \mathrm{TTV}$-negative patients $(32.5 \%)$ were positive for HCV. None of the controls were seropositive for $\mathrm{HCV}$, and HBsAg was not detected in any member of the 2 groups. The frequency of TTV infection among thalassemia patients was in relative agreement with that recorded in similar studies carried out in Egypt by ElMaghraby et al. [25] and Gomma [26], although the virus in the study of El-Maghraby et al. [25] was isolated from healthy individuals at a lower rate than in the present work (20\%). No history of blood transfusion was recorded among the healthy children in the present study, un-

Intervirology 2017;60:102-108 DOI: $10.1159 / 000480507$ 
Fig. 1. Phylogenetic analysis performed with the ORF1 region from the torque teno virus (TTV). The tree was reconstructed from TTV isolates and reference strains via the neighbor-joining method. Representative sequences were used for different genotypes as follows: genotype 1, JaBD28 and TX011; genotype 2a, TS003; genotype 2b, NA004; genotype 2c, PT3; genotype 3, TKB6; genotype 4, TKM1; genotype 5, THEM1; genotype 6, TFC3155; genotype 7, THEM2; genotype 8, THEM3; genotype 9, K70-56; and genotype 10, K66-46. Red dots represent isolates from this study with accession numbers as follows: KY509441KY509445 and MF370189-MF370198.

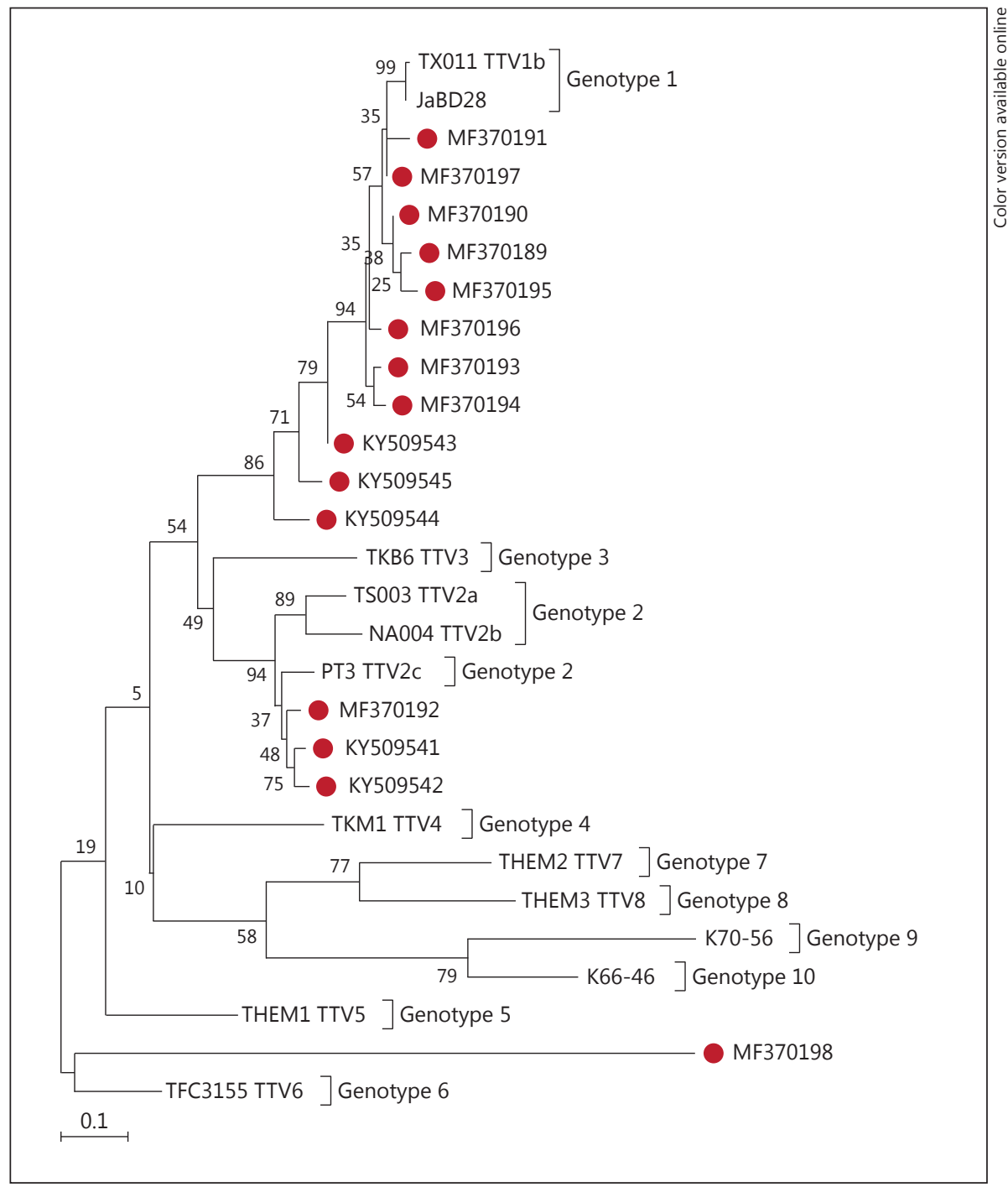

derpinning the postulation that TTV has routes of infection other than transfusion [27]. Concurring with that, several studies have found TTV to be a virus that is transmitted from mother to child $[28,29]$. The high frequency of HCV among TTV-positive thalassemia patients is in agreement with several studies demonstrating the association of the two viruses [30]. The possible association between the 2 viruses could be due to the common transmission route. Furthermore, high TTV loads were correlated with the development of HCC in HCV patients rather than in $\mathrm{HCV}$-alone-infected patients. This augmented HCV pathology caused by TTV coinfection could be due to the similarity between TTV ORF3 and HCV nonstructural protein $5 \mathrm{~A}$, with both proteins influencing the IFN-mediated antiviral response [31].
In the current study, a significant difference in ALT and AST levels was observed between TTV-positive patients and TTV-negative patients. Liver enzymes were also elevated in TTV-positive/HCV-negative patients, which is in accordance with the findings of several studies supporting the potential role of TTV as a hepatic pathogen. For instance, Okamoto et al. [32] showed very high levels of TTV DNA in liver tissues compared to serum levels. However, evaluation of the effect of TTV on the liver based on measurements of ALT and AST levels only is inadequate. Irrespectively of whether TTV is a reason for liver ailment in patients with thalassemia, the exact pathologic mechanism of the virus should be further explained to enable the development of new methodologies to prevent viral transmission. No significant effect of 
age or sex on the levels of the liver enzymes was observed among TTV-positive patients with thalassemia, in agreement with the report of $\mathrm{Hu}$ et al. [33].

More than 30 genotypes of TTV have been identified in various phylogenetic studies, with various geographic distributions as reviewed in the paper by Spandole et al. [5]. Several phylogenetic assignments have been made [34] which have demonstrated that genotypes 1, 2, and 3 are pervasive worldwide [18]. This study is the first in Egypt to elucidate the prevalent genotypes of TTV; 11 of the isolates were close to genotype 1, which included both $\mathrm{HCV}$-positive and $\mathrm{HCV}$-negative patients. On the other hand, there were only 3 genotype 2-related isolates and they were limited to HCV-negative patients, while genotype 6 was only detected in $1 \mathrm{HCV}$-positive case. These results are in agreement with other studies carried out in Saudi Arabia and the United Arab Emirates, where the prevalent genotypes were also 1 and 2 [24, 35].

Further investigations are recommended to augment the association of certain genotypes with HCV seropositivity and its possible impact on the outcome of HCV infection.

\section{Conclusion}

A high prevalence of TTV is reported among children in Egypt, both thalassemic and non-thalassemic, with genotypes 1 and 2 being the most prevalent.

\section{Acknowledgment}

We are grateful to Dr. Ahmed Khairalla, Microbiology and Immunology Department, Faculty of Pharmacy, Beni Suef University, for his technical assistance.

\section{Disclosure Statement}

The authors declare no conflict of interests.

\section{References}

1 Nishizawa T, Okamoto $\mathrm{H}$, Konishi K, Yoshizawa $\mathrm{H}$, Miyakawa $\mathrm{Y}$, Mayumi M: A novel DNA virus (TTV) associated with elevated transaminase levels in posttransfusion hepatitis of unknown etiology. Biochem Biophys Res Commun 1997;241:92-97.

2 King AMQ, Adams MJ, Lefkowitz EJ: Virus Taxonomy: Ninth Report of the International Committee on Taxonomy of Viruses. Amsterdam, Elsevier, 2011, pp 331-341.

3 Mi Z, Yuan X, Pei G, Wang W, An X, Zhang Z, Huang Y, Peng F, Li S, Bai C, Tong Y: Highthroughput sequencing exclusively identified a novel torque teno virus genotype in serum of a patient with fatal fever. Virol Sin 2014;29: 112-118.

4 Hsiao K-L, Wang L-Y, Lin C-L, Liu H-F: New phylogenetic groups of torque teno virus identified in Eastern Taiwan indigenes. PLoS One 2016;11:e0149901.

5 Spandole S, Cimponeriu D, Berca LM, Mihaescu G: Human anelloviruses: an update of molecular, epidemiological and clinical aspects. Arch Virol 2015;160:893-908.

6 Peng YH, Nishizawa T, Takahashi M, Ishikawa T, Yoshikawa A, Okamoto H: Analysis of the entire genomes of thirteen TT virus variants classifiable into the fourth and fifth genetic groups, isolated from viremic infants. Arch Virol 2002;147:21-41.
7 Hussain T, Manzoor S, Waheed Y, Tariq H, Hanif K: Phylogenetic analysis of torque teno virus genome from Pakistani isolate and incidence of co-infection among HBV/HCV infected patients. Virol J 2012;9:320.

8 Popgeorgiev $\mathrm{N}$, Temmam S, Raoult $\mathrm{D}$, Desnues C: Describing the silent human virome with an emphasis on giant viruses. Intervirology 2013;56:395-412.

9 Brajao de Oliveira K: Torque teno virus: a ubiquitous virus. Rev Bras Hematol Hemoter 2015:37:357-358

10 Foschini MP, Morandi L, Macchia S, DalMonte PR, Pession A: TT virus-related acute recurrent hepatitis: histological features of a case and review of the literature. Virchows Arch 2001;439:752-755.

11 Al-Qahtani AA, Alabsi ES, AbuOdeh R, Thalib L, Nasrallah GK: Prevalence of anelloviruses (TTV, TTMDV, and TTMV) in healthy blood donors and in patients infected with HBV or HCV in Qatar. Virol J 2016;13:208.

12 Ikeuchi T, Yokosuka O, Kanda T, Imazeki F, Seta T, Saisho H: Roles of TT virus infection in various types of chronic hepatitis. Intervirology 2001;44:219-223.
13 AbuOdeh R, Al-Mawlawi N, Al-Qahtani AA, Bohol MF, Al-Ahdal MN, Hasan HA, AbuOdeh L, Nasrallah GK: Detection and genotyping of torque teno virus (TTV) in healthy blood donors and patients infected with HBV or HCV in Qatar. J Med Virol 2015;87:11841191.

14 Hettmann A, Demcsák A, Bach Á, Decsi G, Dencs Á, Pálinkó D, Rovó L, Nagy K, Minarovits J, Takács M: Detection and phylogenetic analysis of torque teno virus in salivary and tumor biopsy samples from head and neck carcinoma patients. Intervirology 2016;59: 123-129.

15 Okamoto H, Mayumi M: TT virus: virological and genomic characteristics and disease associations. J Gastroenterol 2001:36:519-529.

16 Simmonds P, Davidson F, Lycett C, Prescott LE, MacDonald DM, Ellender J, Yap PL, Ludlam CA, Haydon GH, Gillon J, Jarvis LM: Detection of a novel DNA virus (TTV) in blood donors and blood products. Lancet 1998;352: 191-195.

17 Kondili LA, Pisani G, Beneduce F, Morace G, Gentili G, Ballati G, Rapicetta M: Prevalence of TT virus in healthy children and thalassemic pediatric and young adult patients. J Pediatr Gastroenterol Nutr 2001;33:629-632.

18 de Castro Amarante MF, Kashima S, Covas DT: TT virus (TTV) genotyping in blood donors and multiple transfused patients in Brazil. Virus Genes 2007;35:503-509. 
19 Maggi F, Fornai C, Morrica A, Casula F, Vatteroni ML, Marchi S, Ciccorossi P, Riente L, Pistello M, Bendinelli M: High prevalence of TT virus viremia in Italian patients, regardless of age, clinical diagnosis, and previous interferon treatment. J Infect Dis 1999;180:838842.

20 Kumar S, Stecher G, Tamura K: MEGA7: Molecular Evolutionary Genetics Analysis version 7.0 for bigger datasets. Mol Biol Evol 2016;33:1870-1874.

21 Saitou N, Nei M: The neighbor-joining method: a new method for reconstructing phylogenetic trees. Mol Biol Evol 1987;4:406-425.

22 Felsenstein J: Confidence limits on phylogenies: an approach using the bootstrap. Evolution 1985;783-791.

23 Tamura K, Nei M, Kumar S: Prospects for inferring very large phylogenies by using the neighbor-joining method. Proc Natl Acad Sci USA 2004;101:11030-11035.

24 Al-Moslih MI, Abuodeh RO, Hu YW: Detection and genotyping of TT virus in healthy and subjects with $\mathrm{HBV}$ or $\mathrm{HCV}$ in different populations in the United Arab Emirates. J Med Virol 2004;72:502-508.
25 El-Maghraby D, EL-Shafie A, El-Sayed S, Alkady M: Detection of TT virus among thalassaemic children with chronic viral hepatitis $B$ and $C$ receiving irradiated and non irradiated RBC. J Radiat Res 2010;3:158-175.

26 Gomma H: Transfusion transmitted virus (TTV) infection in polytransfused Egyptian thalassemic children. J Med Sci 2006;6:833837.

27 Saláková M, Němeček V, König J, Tachezy R: Age-specific prevalence, transmission and phylogeny of TT virus in the Czech Republic. BMC Infect Dis 2004;4:56.

28 Peng Y, Nishizawa T, Takahashi M, Ishikawa T, Yoshikawa A, Okamoto H: Analysis of the entire genomes of thirteen TT virus variants classifiable into the fourth and fifth genetic groups, isolated from viremic infants. Arch Virol 2002;147:21-41.

29 Komatsu H, Inui A, Sogo T, Kuroda K, Tanaka T, Fujisawa T: TTV infection in children born to mothers infected with TTV but not with HBV, HCV, or HIV. J Med Virol 2004; 74:499-506.

30 Fabris P, Biasin MR, Infantolino D, Tositti G, Venza E, Floreani A, Zanetti A, de Lalla F: TTV infection in patients with acute hepatitis of defined aetiology and in acute non-AE hepatitis. J Hepatol 2000;32:661-665.
31 Tokita H, Murai S, Kamitsukasa H, Yagura M, Harada H, Takahashi M, Okamoto H: High TT virus load as an independent factor associated with the occurrence of hepatocellular carcinoma among patients with hepatitis $\mathrm{C}$ virus-related chronic liver disease. J Med Virol 2002;67:501-509.

32 Okamoto H, Akahane Y, Ukita M, Fukuda M, Tsuda F, Miyakawa Y, Mayumi M: Fecal excretion of a nonenveloped DNA virus (TTV) associated with posttransfusion non-A-G hepatitis. J Med Virol 1998;56:128-132.

33 Hu YW, Al-Moslih MI, Al Ali MT, Uzicanin S, Perkins H, Yi QL, Rahimi Khameneh S, Wu J, Brown EG: Clinical outcome of frequent exposure to torque teno virus (TTV) through blood transfusion in thalassemia patients with or without hepatitis $\mathrm{C}$ virus (HCV) infection. J Med Virol 2008;80:365-371.

34 Lemey P, Salemi M, Bassit L, Vandamme AM: Phylogenetic classification of TT virus groups based on the N22 region is unreliable. Virus Res 2002;85:47-59.

35 Al-Mozaini MA, Al-Ahdal MN, Kessie G, Rezeig MA: Molecular epidemiology and genotyping of TT virus isolated from Saudi blood donors and hepatitis patients. Ann Saudi Med 2006;26:444. 